\title{
CD28 and Staphylococcal Enterotoxins Synergize to Induce MHC-Independent T-Cell Proliferation
}

\author{
Jonathan M. Green, $\nmid$ Laurence A. Turka, $\dagger$ Card H. June, $\S$ \\ AND CRAIG B. THOMPSON*†† \\ *H oward Hughes M edical Institute and D epartments of $\uparrow$ Internal M edicine and $\ddagger$ Microbiology/ \\ Immunology, U niversity of M ichigan M edical Center, Ann A rbor, M ichigan 48109-0650; \\ and §Naval M edical Research Center, Bethesda, M aryland
}

Received A pril 9, 1992; accepted July 21, 1992

\begin{abstract}
The bacterial exotoxins staphylococcal enterotoxin A and B (SEA and SEB) mediate disease through their effects on T lymphocytes. In this manuscript we have demonstrated that both SEA and SEB can directly activate purified $\mathrm{T}$ cells in the absence of accessory cells as determined by a transition from $G_{0}$ to $G_{1}$ and induction of IL-2 receptor expression. However, neither SEA nor SEB alone was sufficient to result in T-cell proliferation. The induction of T-cell proliferation by SEB or SEA required the addition of a second costimulatory signal. This could be provided by either accessory cells or monoclonal antibody stimulation of CD28. As previously reported, Tcell proliferation induced by enterotoxin in the presence of accessory cells was partially inhibited by a blocking antibody against class II MHC. In contrast, in purified T cells when costimulation was provided through CD28, proliferation was not inhibited by class II antibody, and HLA-DR expression was not detectable. In addition, costimulation through CD28 was partially resistant to the effects of cyclosporin A. These results demonstrate that CD28 costimulation is sufficient to induce proliferation of enterotoxin-activated $\mathrm{T}$ cells, and that this effect is independent of class II MHC expression. (C)1992 Academic Press, Inc.
\end{abstract}

\section{INTRODUCTION}

In order for $\mathrm{T}$ cells to be activated by conventional antigens, the antigen must first be processed and presented by an antigen presenting cell (APC). This requires proteolysis of the antigen and incorporation of the resulting peptide fragments into the binding groove of an MHC molecule. The antigen-MHC complex is expressed on the surface of the APC where it can be recognized by T cells bearing a T-cell receptor (TCR) with the appropriate specificity (for review see (1)). This interaction leads to TCR-mediated signal transduction events that initiate T-cell activation. However, recent evidence suggest that TCR stimulation alone is an insufficient stimulus to lead to T-cell proliferation $(2,3)$. This observation has led to the hypothesis that an additional signal(s) provided by the APC is required to induce T-cell proliferation. In the absence of this second signal, the $\mathrm{T}$ cell will not proliferate and may be rendered refractory to further antigenic challenge (4).

The CD28 signal transduction pathway has been identified as a potential candidate for providing the second signal necessary for successful $\mathrm{T}$-cell activation. If $\mathrm{T}$ cells are activated using submitogenic doses of anti-CD3 monoclonal antibodies, they can be 
stimulated to proliferate by antibody stimulation of CD28 (5). A natural ligand for CD28 has recently been identified and is the B7/BB 1 antigen on the surface of activated $\mathrm{B}$ cells and interferon-y-induced macrophages (6). Costimulation of cells with submitogenic doses of Con A and B7-transfected CHO cells can also induce T-cell proliferation (7). Although these results show synergy between TCR or mitogen activation and the CD28 activation pathway, neither means of primary activation are able to mimic antigen activation events that might occur in vivo.

Recently, an interesting group of protein antigens termed superantigens has been characterized which is capable of activating large numbers of peripheral blood $\mathrm{T}$ cells. Unlike nominal antigens which activate on the order of 1 in 10,000 cells, superantigens may activate anywhere from 10 to $30 \%$ of T cells. Bacterially derived superantigens include the staphylococcal enterotoxins A and B (SEA and SEB), toxic shock syndrome toxin 1, exfoliative toxin, and other bacterial proteins (8). In addition, the Mls antigens have recently been characterized to be superantigens which appear to be encoded in a unique open reading frame of some murine retroviruses (9-1 1). The ability of superantigens to activate such a large percentage of $\mathrm{T}$ cells is due to their specificity for all $\mathrm{T}$ cells which bear a particular V region on the $\beta$ chain of the TCR (8). Superantigens have also been shown to bind to class II MHC molecules. Superantigens appear to bind MHC outside the peptide binding groove (12). Traditional processing is not required for binding to MHC. In fact, chemically fixed APC retain their ability to bind and present superantigen $(13,14)$. It is thought, however, that the ability of superantigens to stimulate $\mathrm{T}$ cells is dependent upon the TCR interacting with the superantigen presented on the surface of an APC. Although this result has been interpreted to mean that the required interaction between the T cell and APC is a TCRsuperantigen-MHC class II complex, APCs can also express other costimulatory molecules such as B7 which could potentiate a T cell's response to superantigens. Consistent with this possibility, unlike nominal antigen responses, superantigen responses are not restricted to APCs that express self-encoded MHC molecules. In fact, even APC expression of xenogeneic class II MHC has been shown to support enterotoxin-induced T-cell proliferation (15).

This lack of stringency in the MHC requirement for T-cell activation by superantigen suggested that there might be an additional or alternative role played by the accessory cell. We therefore chose to investigate the effect of the CD28 activation pathway on the responses of purified $\mathrm{T}$ cells to superantigen activation. In this manuscript, we demonstrate that CD28 costimulation synergizes with superantigen to activate $\mathrm{T}$ cells in a class II-independent manner. Our data indicate that superantigens are capable of directly stimulating the $\mathbf{T}$ cell to enter the $\mathrm{G}_{1}$ phase of the cell cycle in the absence of MHC presentation, and that provision of a second signal through CD28 allows full progression through the cell cycle.

\section{MATERIALS AND METHODS}

Isolation of $T$ cells. Peripheral blood was drawn from normal human volunteers. The mononuclear cell fraction was obtained by density gradient centrifugation through a Ficoll-Hypaque (Pharmacia) cushion. This fraction was used in experiments utilizing peripheral blood mononuclear cells (PBMCs). Purified resting T cells were obtained by incubating the mononuclear cells with an antibody cocktail directed against B cells, monocytes, and activated $\mathrm{T}$ cells. The antibody-coated cells were then removed by 
incubation with a goat anti-mouse immunoglobulin-coated magnetic beads (Advanced Magnetics Inc.) as previously described (16). This method has routinely yielded a population $>99 \% \mathrm{CD}^{+}$by flow cytometry.

Proliferation assays. Proliferation was measured by culturing $5 \times 10^{5}$ purified $\mathrm{T}$ cells or PBMCs in each well of a 96-well microtiter plate. The final culture volume was $200 \mu$ l of RPMI 1640 (GIBCO) supplemented with 10\% FCS, penicillin (100 U/ $\mathrm{ml}$ ), streptomycin $(100 \mu \mathrm{g} / \mathrm{ml})$, and $2 \mathrm{~m} M$ L-glutamine. SEA, SEB (Toxin Technologies), and cyclosporin A (Sandoz) were added in the indicated doses at the initiation of the culture. Anti-CD28 monoclonal antibody (mAb 9.3, gift from J. Ledbetter), anti-HLA-DR monoclonal antibody (mAb L243, gift from J. Ledbetter), and antiHLA-DQ monoclonal antibodies (mAbs 309 1, 3 101, 3 102, 3 120, kind gift of E. Milford) were added at the start of the culture period. Tritiated thymidine $\left(\left[{ }^{3} \mathrm{H}\right] \mathrm{TdR}\right.$, ICN) was included at a concentration $1 \mu \mathrm{Ci}$ per well for the final $8 \mathrm{hr}$ of the culture. The cells were harvested onto glass microfiber filter strips (Whatman) after $72 \mathrm{hr}$ using a PHD cell harvester (Cambridge Technologies) and counted on a liquid scintillation counter (LKB). All values are expressed as the mean cpm \pm standard deviation of triplicate or quadruplicate cultures.

Flow cytometry. One-milliliter cultures of T cells were incubated with medium alone, SEA $(100 \mathrm{ng} / \mathrm{ml})$, or SEB $(1 \mu \mathrm{g} / \mathrm{ml})$, SEA or SEB plus anti-CD28 antibody ( 1 $\mu \mathrm{g} / \mathrm{ml})$, or PMA $(3 \mathrm{ng} / \mathrm{ml})$ plus anti-CD28 antibody $(1 \mu \mathrm{g} / \mathrm{ml})$ at $37^{\circ} \mathrm{C}$ for $72 \mathrm{hr}$. Aliquots of each sample were stained with acridine orange (Polysciences) for cell cycle analysis (17), FITC-conjugated anti-IL2 receptor antibody (Coulter), FITC-conjugated anti-HLA-DR antibody (Becton-Dickinson), or an isotype-matched irrelevant antibody (Becton-Dickinson). Each sample was analyzed on a FACScan flow cytometer (BectonDickinson).

\section{RESULTS}

CD28 provides costimulatory activity for superantigen-activated purified $T$ cells. Highly purified T cells were cultured with graded concentrations of either SEA $(0.1$ $\mathrm{ng} / \mathrm{ml}$ to $1 . \mathrm{O} \mu \mathrm{g} / \mathrm{ml})$ or SEB $(0.01$ to $100 \mu \mathrm{g} / \mathrm{ml})$. Replicate cultures were prepared in which a stimulatory antibody to CD28 was added. Cultures were then assayed for $\left[{ }^{3} \mathrm{H}\right] \mathrm{TdR}$ incorporation after $72 \mathrm{hr}$ of culture. As shown in Fig. 1, treatment with SEB alone failed to induce thymidine incorporation above control cultures. However, the addition of anti-CD28 antibody resulted in significant proliferation to graded doses of SEB. Treatment with anti-CD28 antibody alone had no effect (data not shown). The lack of accessory cells was verified by an absence of proliferation to PHA. Identical results were obtained using SEA (Fig. 3A and data not shown).

Stimulation with SEA or SEB leads to cell cycle entry. Since CD28 stimulation alone does not induce T-cell cycle entry, the observation that CD28 provided costimulatory activity for T cells treated with either SEA or SEB suggested that these enterotoxins could induce cell cycle entry in purified T cells. In order to examine this we stimulated purified T-cell cultures with SEB alone or with SEB plus anti-CD28 monoclonal antibody and stained the cells with acridine orange for cell cycle analysis. Unstimulated cells were run simultaneously in order to determine the $G_{0} / G_{1}$ interface. Concomitantly, aliquots were stained with FITC-conjugated anti-IL-2 receptor antibody. As shown in Fig. 2, treatment with enterotoxin alone for $48 \mathrm{hr}$ resulted in progression of greater than $10 \%$ of the $T$ cells from $G_{0}$ to $G_{1}$ as determined by an 


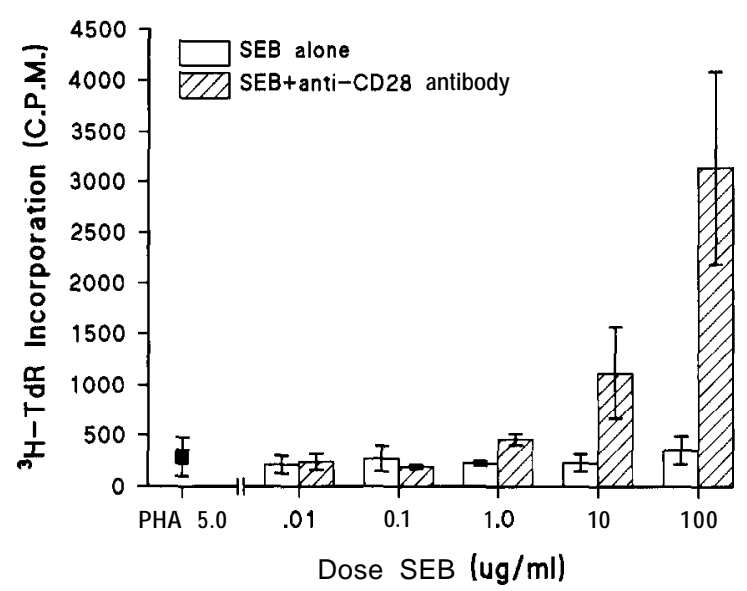

FIG. 1. Purified resting T cells were stimulated with graded concentrations of SEB alone or SEB plus antiCD28 antibody. The cultures were pulsed with $\left[{ }^{3} \mathrm{H}\right] \mathrm{TdR}$ for the final $8 \mathrm{hr}$ of a 72 -hr culture and incorporated thymidine determined by liquid scintillation counting as described under Materials and Methods. Each condition was performed in quadruplicate, and the data are presented as the means \pm standard deviation. Control cultures treated with PHA $5.0 \mu \mathrm{g} / \mathrm{ml}$ did not incorporate significant amounts of $\left[{ }^{3} \mathrm{H}\right] \mathrm{TdR}$ verifying accessory cell depletion.

increase in RNA staining with no increase in DNA content. Similarly, enterotoxin alone induced IL-2 receptor expression in $15 \%$ of the cells at $72 \mathrm{hr}$. In contrast, when the anti-CD28 monoclonal antibody was present, a significant proportion of the cells that had left the $G_{0}$ stage of the cell cycle were found to have increased their DNA content and thus are in either the $\mathrm{S}$ or $\mathrm{G}_{2} \mathrm{M}$ phases of the cell cycle. These data indicate that stimulation with SEB alone is sufficient to activate the $\mathrm{T}$ cell but delivers an inadequate signal for complete progression through the cell cycle. Provision of a second signal by simultaneous stimulation of the CD28 pathway allowed the cell to progress to $\mathbf{S}$ phase and proliferate.

Proliferation of $T$ cells stimulated by SEA and anti-CD28 antibody is resistant to cyclosporin A. CD28 has been shown to utilize a signal transduction pathway that is resistant to the effects of cyclosporin $\mathrm{A}(\mathrm{CsA})$ when the initial signal is provided by PMA, and partially resistant to CsA when cells are initially activated through the Tcell receptor (16). In order to further examine the pathways involved in T-cell activation by enterotoxin, we included cyclosporin A $(1 \mu \mathrm{g} / \mathrm{ml})$ in cultures activated by SEA and SEA plus anti-CD28 antibody. As for SEB, SEA alone did not induce thymidine incorporation whereas addition of antibody against CD28 resulted in significant proliferation (Fig. 3A). Even in the presence of cyclosporin A there was a dose-dependent increase in proliferation when cultures were activated by a combination of SEA and anti-CD28 antibody (Fig. 3B). Control cultures activated with PMA plus anti-CD28 antibody were resistant to cyclosporin $\mathrm{A}$ and activation by PMA plus ionomycin was sensitive to cyclosporin A (data not shown).

Activation by SEB plus anti-CD28 is independent of class II MHC. Previous work has demonstrated that the staphylococcal enterotoxins are capable of simultaneously binding the TCR and class II MHC molecules on the surface of antigen presenting cells $(18,19)$. The observation that proliferation was not observed unless APCs were present in the culture was interpreted to mean that T-cell activation by superantigen 


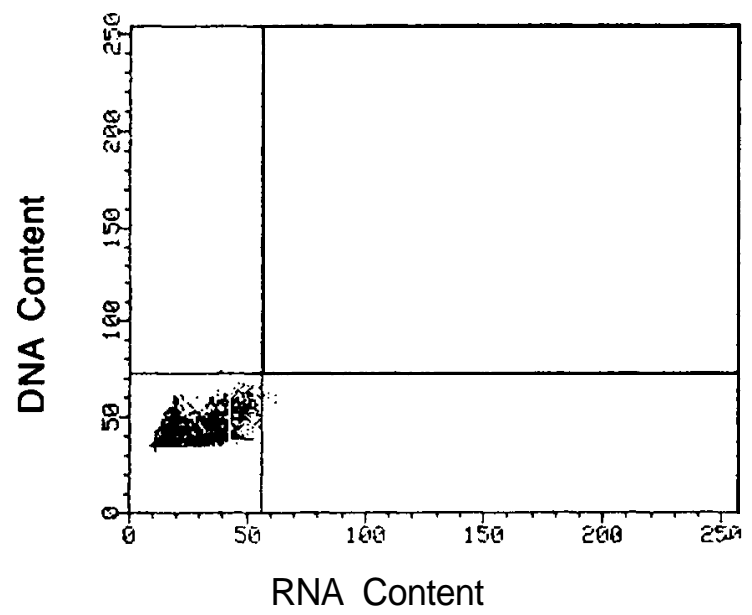

Resting

$\% G_{0} \quad 99.5$

$\% G_{1} \quad 0.4$

$\% S / G_{2} M \quad 0.0$

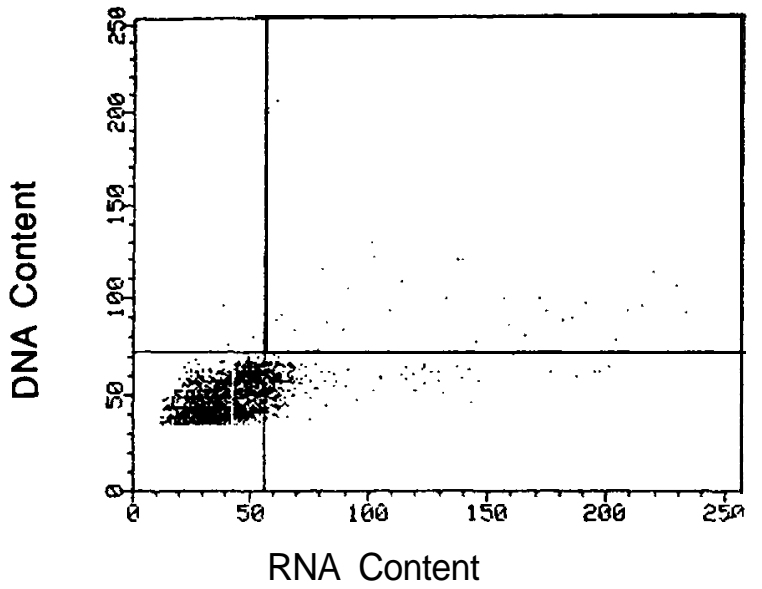

SEB $(1 \mu \mathrm{g} / \mathrm{ml})$

$\% \mathrm{G}_{0} \quad 87.1$

$\% \mathrm{G}, \quad 11.3$

$\% S / G_{2} M 1.4$

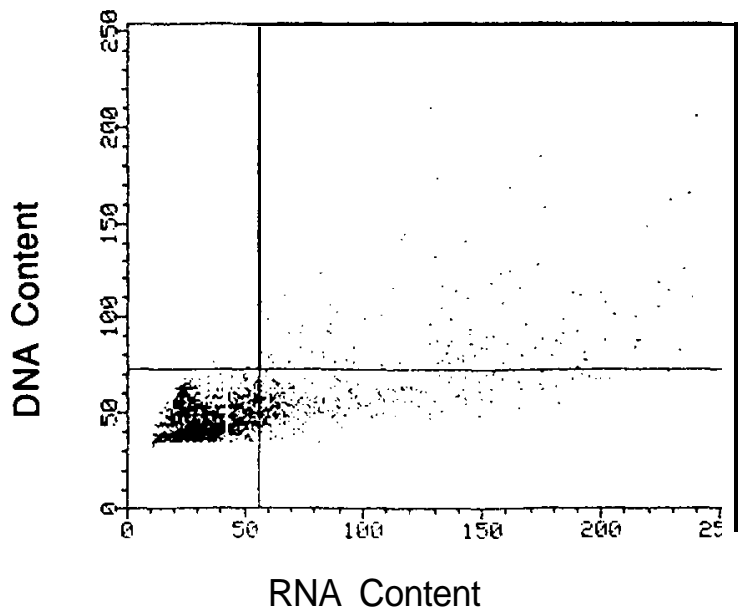

$\underline{\mathrm{SEB}+\mathrm{aCD} 28 \mathrm{Ab}}$

$\% \mathrm{G}_{0} \quad 78.6$

$\% G_{1} \quad 16.4$

$\% S / G_{2} M 4.5$

FIG. 2. Purified resting T cells were treated with SEB $(\mathrm{I} \mu \mathrm{g} / \mathrm{ml})$ or SEB $(\mathrm{I} \mu \mathrm{g} / \mathrm{ml})$ plus anti-CD28 antibody $(1 \mu \mathrm{g} / \mathrm{ml})$ for $48 \mathrm{hr}$ and aliquots were stained with acridine orange for cell cycle analysis. Unstimulated cells were analyzed simultaneously to determine the $G_{0} / G_{1}$ interface. Those with an increased RNA content but unchanged DNA content were considered G,-phase cells. Cells with increases in both RNA and DNA content were considered in $\mathrm{S}$ or $\mathrm{G}_{2} \mathrm{M}$ phases. 


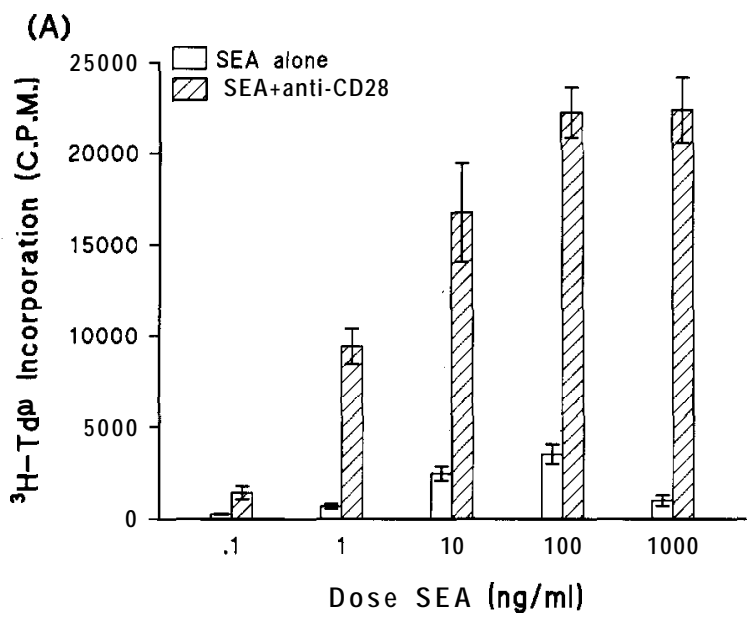

(B)

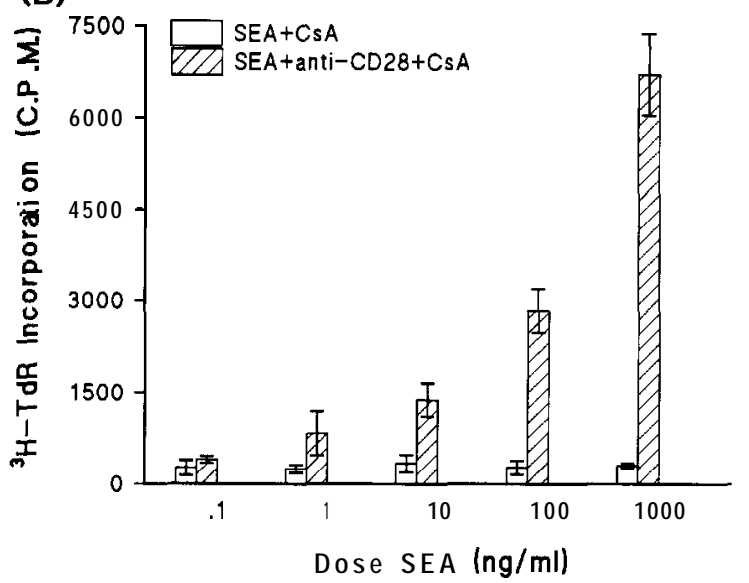

FIG. 3. (A) Purified T cells were stimulated with graded concentrations of SEA alone or SEA plus antiCD28 antibody and [ $\left.{ }^{3} \mathrm{H}\right] \mathrm{TdR}$ incorporation was determined as described under Materials and Methods. (B) Identical cultures as in A were prepared with the addition of cyclosporin A (CsA; $1 \& \mathrm{ml})$. Each point is expressed as the mean \pm standard deviation. Proliferation of control cultures stimulated with PMA plus ionomycin was inhibited by CsA, whereas the proliferation of cultures activated by PMA plus anti-CD28 antibody was resistant to CsA (data not shown).

is dependent upon class II MHC expression (14, 20, 21). Our observation that highly purified $\mathrm{T}$ cells could be induced to proliferate by simultaneous stimulation with enterotoxin and anti-CD28 antibody suggested that class II MHC may not be absolutely required for superantigen activation of $\mathrm{T}$ cells. Alternatively, activated T cells can express class II MHC and thus might provide class II-dependent superantigen presentation to other T cells in trans. To examine this possibility, we included a blocking antibody against HLA-DR, monoclonal antibody L243, in cultures of T cells and PBMCs activated by enterotoxin or enterotoxin plus anti-CD28 antibody (Fig. 4). No significant proliferation was observed with SEB alone. As shown previously, inclusion of anti-CD28 antibody allows SEB to induce T-cell proliferation in a dose-dependent manner. There was no decrease in proliferation when anti-class II antibody was included 


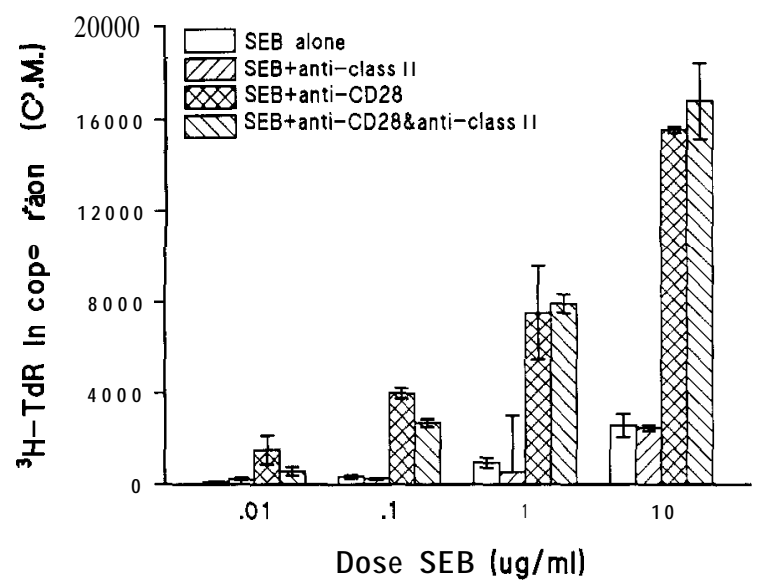

FIG. 4. Purified resting T cells were treated with either SEB alone or SEB plus anti-CD28 antibody in the presence or absence of a blocking monoclonal antibody to HLA-DR, mAb L243, and [ $\left.{ }^{3} \mathrm{H}\right] \mathrm{TdR}$ incorporation was determined. Each point is expressed as the mean \pm the standard deviation of triplicate or quadruplicate cultures. Treatment with $5.0 \mu \mathrm{g} / \mathrm{ml}$ PHA did not result in an increase in $\left[{ }^{3} \mathrm{H}\right] \mathrm{TdR}$ over that of unstimulated cells (data not shown).

in the cultures at doses of $1 . \mathrm{O}$ or $10 \mu \mathrm{g} / \mathrm{ml}$ (data for $10 \mu \mathrm{g} / \mathrm{ml}$ not shown). In contrast, the proliferation of PBMCs isolated from the same donor and stimulated with enterotoxin was significantly inhibited by anti-class II antibody (Fig. 5). To examine whether HLA-DQ was involved in presentation of SEA or SEB to T cells, a cocktail of monoclonal antibodies that recognize all DQ alleles was added to cultures of enterotoxin activated T cells and PBMCs (Table 1). Inclusion of the antibodies did not inhibit the proliferation of purified T cells activated by SEA or SEB plus anti-CD28 but did inhibit the proliferation of enterotoxin activated PBMCs. In addition, we examined HLA-DR expression at 24 and $72 \mathrm{hr}$ by purified T cells activated with SEA ( 0.1 or

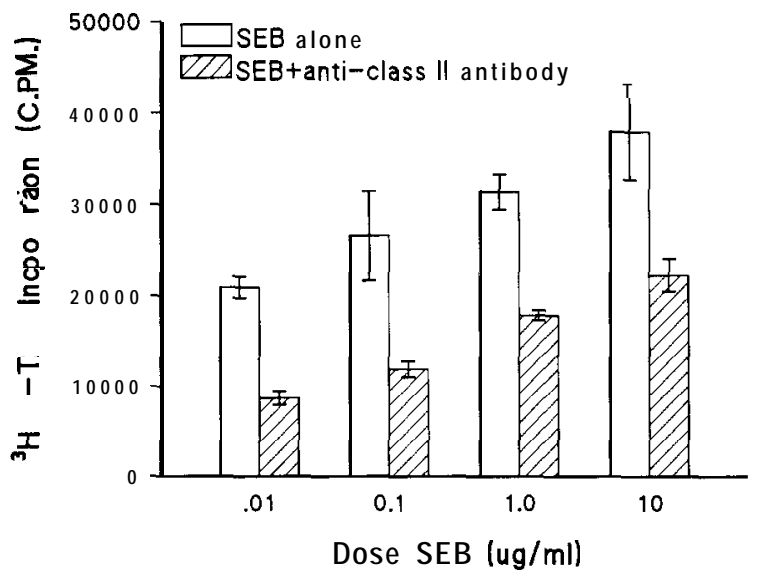

FIG. 5. Peripheral blood mononuclear cells were treated with SEB alone or SEB plus a blocking antibody to HLA-DR, mAb L243. Incorporation of [ $\left.{ }^{3} \mathrm{H}\right] \mathrm{TdR}$ was determined as previously described. Each point represents the mean \pm standard deviation. 
TABLE I

Effect of Anti-HLA-DQ

\begin{tabular}{|c|c|c|c|}
\hline \multicolumn{2}{|c|}{ Experiment 1} & \multicolumn{2}{|c|}{ Experiment 2} \\
\hline Purified T cell & SEB $100(\& \mathrm{ml})$ & Purified T cell & SEA $1.0(\mathrm{ng} / \mathrm{ml})$ \\
\hline $\begin{array}{l}\text { Media } \\
+\mathrm{aCD} 28 \\
+\alpha \mathrm{CD} 28+\alpha \mathrm{DQ} \\
\mathrm{t} \alpha \mathrm{CD} 28+\alpha \mathrm{DR} \\
+\alpha \mathrm{CD} 28+\alpha \mathrm{DQ} / \alpha \mathrm{DR}\end{array}$ & $\begin{array}{r}4,633 \pm 395 \\
11,182 \pm 495 \\
10,910 \pm 1194 \\
9,352 \pm 1196 \\
9,121 \pm 693\end{array}$ & $\begin{array}{l}\text { Media } \\
+\alpha \mathrm{CD} 28 \\
+\alpha \mathrm{CD} 28+\alpha \mathrm{DQ}\end{array}$ & $\begin{array}{r}1,594 \pm 108 \\
11,130 \pm 649 \\
11,825 \pm 1228\end{array}$ \\
\hline & & PBMCs & SEA $1.0(\mathrm{ng} / \mathrm{ml})$ \\
\hline & & $\begin{array}{l}\text { Media } \\
+\alpha \mathrm{DQ} \\
\mathrm{t} \alpha \mathrm{DR} \\
+\alpha \mathrm{DQ} / \alpha \mathrm{DR}\end{array}$ & $\begin{array}{l}76,502 \pm 7156 \\
52,316 \pm 5839 \\
50,073 \pm 6314 \\
26,847 \pm 2306\end{array}$ \\
\hline
\end{tabular}

Note. Purified resting T cells were activated with SEA or SEB alone or in combination with anti-CD28 antibody. Antibodies to HLA-DR and/or HLA-DQ (28) were added at the start of culture as indicated and proliferation measured at $72 \mathrm{hr}$ as described under Material and Methods. Data are expressed as cpm, means \pm SD.

$1.0 \mathrm{ng} / \mathrm{ml}$ ) with and without CD28 costimulation. There was no expression of HLA$\mathrm{DR}$ in either condition as determined by flow cytometry. This indicated that the Tcell proliferation induced by enterotoxin plus anti-CD28 is not dependent on presentation by an MHC class II molecule.

\section{DISCUSSION}

A substantial body of data has been accumulated describing the process of T-cell activation by superantigens $(8,22)$. This family of proteins appears to be important in a number of disease states. Bacterial exotoxins mediate the toxicity of staphylococcal enteritis (23), toxic shock syndrome (24), and have been implicated in the pathogenesis of rheumatoid arthritis (25). It has been suggested that expression of a superantigen may mediate the T-cell depletion seen in HIV infection (26). An understanding of their mechanisms of action will be crucial to developing effective therapeutic strategies.

The observation has been made by many laboratories that $\mathrm{T}$-cell activation by superantigen requires the presence of an APC in order to lead to T-cell proliferation (20). The demonstration that superantigens are also capable of binding to class II MHC molecules has led to the belief that class II is required for T-cell activation by superantigen. However, one group has recently shown that superantigen can induce T-cell cytotoxicity in a class II-independent system (27). In this paper we have treated highly purified $\mathrm{T}$ cells with the superantigens SEA or SEB. The absence of accessory cells has been demonstrated by the lack of proliferation to PHA and the absence of MHC class II-positive cells as assayed by flow cytometry. Treatment of T cells with SEA or SEB led to entry into the $\mathrm{G}_{1}$ phase of the cell cycle and IL-2 receptor expression but not proliferation. When an additional signal was provided to the T cells via stim- 
ulation of the CD28 pathway, the cells then went on to proliferate, as demonstrated by incorporation of $\left[{ }^{3} \mathrm{H}\right] \mathrm{TdR}$ and increased DNA staining with flow cytometry. The proliferation induced by enterotoxin plus CD28 stimulation was partially resistant to the effects of cyclosporin A.

To verify that the observed proliferation was indeed independent of class II expression, we included monoclonal antibodies to HLA-DR and HLA-DQ in the cultures. Both SEA and SEB have been shown to bind to HLA-DR (19). Proliferation of purified $T$ cells was unaffected by the addition of the antibody while PBMCs isolated from the same individual and activated with enterotoxin alone were significantly inhibited. Consistent with these data, SEA did not induce cell surface expression of HLA-DR.

The observation that PBMCs were partially inhibited by inclusion of a blocking class II antibody implies a role for MHC molecules in T-cell activation by enterotoxin in the presence of APCs. Several possible explanations exist. This may be in order to facilitate an interaction of B7 with CD28 rather than an absolute requirement for class II. Other possibilities are that the binding to MHC allows for more efficient crosslinking of the TCR or that the binding to MHC actually induces B7 expression on the APC.

The data presented demonstrate that $\mathrm{T}$ cells can be activated and induced to enter the $\mathrm{G}_{1}$ phase of the cell cycle by enterotoxin in the absence of class II MHC expression and that CD28 costimulation is sufficient to support proliferation in this circumstance. It will now be important to determine whether this interaction is necessary for T-cell activation by superantigen in vivo. Should this prove to be the case, it may lead to new therapeutic strategies for superantigen-mediated disease.

\section{ACKNOWLEDGMENTS}

The authors thank P. Reynolds for reviewing the manuscript and J. Pickett for expert assistance in the preparation of this manuscript. J. M. Green is supported by an American Lung Association Research Training Award. This work was supported in part by the Naval Medical Research Institute.

\section{REFERENCES}

1. Mat-rack, P., and Kappler, J., Science 238, 1073, 1987.

2. Mueller, D. L., Jenkins, M. K., Chiodetti, L., and Schwartz, R. H., J. Immunol. 144, 3701, 1990.

3. Jenkins, M. K., Chen, C., Jung, G., Mueller, D. L., and Schwartz, R. H., J. Immunol. 144, 16, 1990.

4. Schwartz, R. H., Science 248, 1349, 1990.

5. Damle, N. K., Doyle, L. V., Grosmaire, L. S., and Ledbetter, J. A., J. Immunol. 140, 1753, 1988.

6. Linsley, P. S., Clark, E. A., and Ledbetter, J. A., Proc. Natl. Acad. Sci. USA 87, 503 I, 1990.

7. Reiser, H., Freeman, G. J., Razi-Wolf, Z., Gimmi, C. D., Benacerraf, B., and Nadler, L. M., Proc. Nat/. Aced. Sci. USA 89, 27 1, 1992.

8. Marrack, P., and Kappler, J., Science 248, 705, 1990.

9. Frankel, W. N., Rudy, C., Coffin, J. M., and Huber, B. T., Nature 349, 526, 1991.

10. Woodland, D. L., Happ, M. P., Gollob, K. J., and Palmer, E., Nature 349, 629, 1991.

11. Dyson, P. J., Knight, A. M., Fairchild, S., Simpson, E., and Tomonari, K., Nature 349, 531, 1991.

12. Herman, A., Labrecque, N., Thibodeau, J., Marrack, P., Kappler, J. W., and Sekaly, R.-P., Proc. Natl. Acad. Sci. USA 88, 9954, 1991.

13. Yagi, J., Baron, J., Buxser, S., and Janeway, C. A., J. Immunol. 144, 892, 1990.

14. Fleischer, B., and Schrezenmeier, H., J. Exp. Med. 167, 1697, 1988.

15. Fleischer, B., Schrezenmeier, H., and Conradt, P., Cell. Immunol. 120, 92, 1989.

16. June, C. H., Ledbetter, J. A., Gillespie, M. M., Lindsten, T., and Thompson, C. B., Mol. Cell. Biol. 7, 4472, 1987.

17. Darzynkiewicz, Z., Methods Cell Biol. 33, 285, 1990.

18. Herrmann, T., Accolla, R. S., and MacDonald, H. R., Eur. J. Immunol. 19, 217 1, 1989.

19. Chintagumpala, M. M., Mollick, J. A., and Rich, R. R., J. Immunol. 147, 3876, 1991. 
20. Carlsson, R., Fischer, H., and Sjogren, H. O., J. Immunol. 140, 2484, 1988.

21. Herman, A., Croteau, G., Sekaly, R.-P., Kappler, J., and Marrack, P., J. Exp.Med. 172, 709, 1990.

22. Mollick, J. A., Chintagumpala, M., Cook, R. G., and Rich, R. R., J. Immunol. 146,464, 1991.

23. Alber, G., Hammer, D. K., and Fleischer, B., J. Immunol. 144, 4501, 1990.

24. Schlievert, P. M., Shands, K. N., Dan, B. B., Schmid, G. P., and Nishimura, R. D., I. Infect. Dis. 143, 509, 1981.

25. Paliard, X., West, S. G., Lafferty, J. A., Clements, J. R., Kappler, J. W., and Marrack, P., Kotzin, B. L., Science 253, 325, 1991.

26. Imberti, L., Sottini, A., Bettinardi, A., Puoti, M., and Primi, D., Science 254, 860, 1991.

27. Herrmann, T., Romero, P., Sartoris, S., Paiola, F., Accolla, R. S., Maryanski, J. L., and MacDonald, H. R., J. Immunol. 146, 2504, 1991.

28. Milford, E. L., Park, M. S., Lalouel, J.-M., Kennedy, L. J., and Yunis, E. J., In "Immunobiology of the HLA, Volume 1, Histocompatibility Testing 1987” (B. Dupont, Ed.), pp. 93-98. Springer-Verlag, New York, 1987. 